\title{
A New Model of Pneumocystis carinii Infection in Mice Selectively Depleted of Helper T Lymphocytes
}

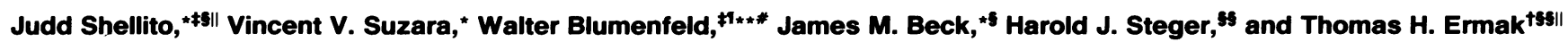 \\ Sections of ${ }^{*}$ Respiratory Care, ${ }^{\S}$ Cell Biology and Aging, and ${ }^{\natural}$ Anatomic Pathology, ${ }^{* *}$ the Center for Immunochemistry, and ${ }^{\ddagger}$ the \\ Veterans Administration AIDS Research Center, Department of Veterans Affairs Medical Center, San Francisco, California; and ${ }^{\S}$ the \\ Cardiovascular Research Institute and Departments of "Medicine and "Laboratory Medicine, \\ University of California, San Francisco, California 94143
}

\begin{abstract}
Pulmonary infections with Pneumocystis carinii are an important cause of morbidity and mortality in patients with AIDS. $P$. carinii infections are seen in patients with decreased numbers of helper $\mathbf{T}$ lymphocytes, suggesting that these cells are important in preventing infection. To test this hypothesis, we sought to establish experimental infection with $P$. carinii in mice selectively depleted of helper $T$ lymphocytes. Weekly injections of a monoclonal anti-CD4 antibody produced sustained depletion of helper $T$ lymphocytes from blood and lymphoid organs. To establish pulmonary infection, lymphocytedepleted mice were then given intratracheal inoculations of $\boldsymbol{P}$. carinii organisms derived from the lungs of chronically infected athymic mice. Pulmonary infection with $P$. carinii was demonstrable in the antibody-treated mice and was centered around the conducting airways. Infection was persistent for up to 3 mo with continued antibody treatments, and yet could be cleared from the lungs if antibody treatments were discontinued. This experimental model of $P$. carinii infection permits the study of infection associated with a specific immune defect and implicates the helper $T$ lymphocyte as a critical cell in host defense against this pathogen. (J. Clin. Invest. 1990. 85:1686-1693.) pneumonia - Pneumocystis carinii immunosuppression
\end{abstract}

\section{Introduction}

Pneumocystis carinii is an important cause of pneumonia in immunocompromised patients (1), particularly those with AIDS (2). Although $P$. carinii pneumonia can be treated with trimethoprim-sulfamethoxazole or pentamidine, fatality rates with initial infection range from 15 to $60 \%(3,4)$. Improvement in the therapy of $P$. carinii pneumonia may require a better understanding of the pathogenesis of infection and how immunosuppression permits infection.

Because $P$. carinii can be maintained only in short-term in vitro culture (5-7), investigation into host defense against in-

Address all correspondence to Dr. Judd Shellito, Section of Pulmonary and Critical Care Medicine, LSU Medical Center, 1542 Tulane Avenue, New Orleans, LA 70112.

Received for publication 27 September 1989 and in revised form 10 January 1990

J. Clin. Invest.

(C) The American Society for Clinical Investigation, Inc.

0021-9738/90/05/1686/08 \$2.00

Volume 85, May 1990, 1686-1693 fection has been heavily dependent on animal models. However, existing animal models preclude definitive study of host defenses against $P$. carinii because they require either animals with congenital immunosuppression $(8,9)$ or corticosteroid treatment (10), which has multiple effects on the immune system. Because decreased numbers of helper $T$ lymphocytes are typically seen in AIDS (11), this study was undertaken to determine whether $P$. carinii pneumonia could be established experimentally in mice depleted of helper $\mathrm{T}$ lymphocytes. Surface expression of the CD4 molecule correlates with helper-inducer function in lymphocytes (12). Weekly injection of mice with an anti-CD4 monoclonal antibody depletes circulating blood and lymphoid tissues of helper $\mathrm{T}$ lymphocytes $(13,14)$. Selective depletion of CD4-positive cells has been used previously to examine host defense mechanisms against Leishmania major (15), Giardia muris (16), Trypanosoma cruzi (17), andHistoplasma capsulatum (18). In the experiments reported here, we depleted normal BALB/c mice of CD4-positive lymphocytes by weekly injection with anti-CD4 monoclonal antibody and then instilled $P$. carinii organisms into the lungs by intratracheal inoculation. Our goals were to establish infection in mice that was reproducible, persistent, and associated with a discrete and potentially reversible immune defect. The results indicate that $P$. carinii pneumonia can be reproducibly established in such lymphocyte-depleted mice, and that the pulmonary infection is persistent if antiCD4 treatment is maintained but reversible if antibody treatment is discontinued.

\section{Methods}

Animals. Virus-free, male BALB/c mice were purchased at 4-5 wk of age from Bantin \& Kingman, Inc. (Fremont, CA). Male athymic (nu/ $n u$ ) mice with chronic $P$. carinii infection were purchased from Charles River Breeding Laboratories, Inc. (K95 colony; Kingston, NY). All mice were housed in the Animal Care Facility of the Veterans Administration (VA) Medical Center, San Francisco, in filtered cages and laminar flow hoods. The mice were provided with sterile mouse chow and sterile water ad lib. This research was approved by the Animal Studies Committee at the VA Medical Center, San Francisco.

Anti-CD4 monoclonal antibody. The hybridoma GK1.5, which produces a rat $\mathrm{IgG}_{2 \mathrm{~b}}$ monoclonal antibody against CD4 (12), was obtained from the American Type Culture Collection (Rockville, MD) and harvested as ascites from uninfected athymic $(n u / n u)$ mice. The antibody was partially purified by ammonium sulfate precipitation, dialyzed against PBS, and quantified by protein electrophoresis and measurement of optical density $(14,19)$. To deplete mice of helper $\mathrm{T}$ lymphocytes, mice received weekly intraperitoneal injections of $0.1 \mathrm{mg}$ 
anti-CD4 antibody in $0.2 \mathrm{ml} \mathrm{PBS}$. This dose of anti-CD4 antibody was chosen to target peripheral blood and lymphoid organs but not the thymus (Ermak, T. H., unpublished results). Higher doses of anti-CD4 modulate surface $\mathrm{CD} 4$ on thymocytes and alter differentiation pathways for $\mathrm{T}$ lymphocytes within the thymus (20-22), whereas lower doses stimulate production of antibodies against the administered antibody (23).

Preparation of $P$. carinii inoculum. $P$. carinii-infected athymic mice were killed by a lethal dose of intraperitoneal pentobarbital ( 400 $\mathrm{mg} / \mathrm{kg}$ ) and exsanguinated by severing the abdominal aorta. Lungs were removed and touch preparations stained with Diff-Quik (AHS del Caribe, Inc., Aguada, PR) were examined for bacterial and fungal organisms. Lungs free of bacteria or fungi were selected for the inoculum and frozen at $-20^{\circ} \mathrm{C}$ for $2 \mathrm{~h}$. After freezing, the lungs from 4-10 athymic mice were pooled into PBS and homogenized in a tissue stomacher (model 80; Tekmar Co., Cincinnati, $\mathrm{OH}$ ). This homogenate was then passed through a layer of surgical gauze and centrifuged at $500 \mathrm{~g}$ for $10 \mathrm{~min}$ at $5^{\circ} \mathrm{C}$. The pellet was then resuspended in PBS $(0.5$ $\mathrm{ml}$ PBS for each mouse lung added), and this suspension was used as the intratracheal inoculum. Microscopic counts of $P$. carinii cyst forms were performed on 5- $\mu \mathrm{l}$ smears of the inoculum stained with DiffQuik, and the concentration was adjusted to at least $2 \times 10^{5}-2 \times 10^{6}$ cysts/ml PBS. To insure viability of the injected $P$. carinii organisms, the inoculum was injected into recipient mice on the same day it was prepared.

Intratracheal inoculation of $P$. carinii. To inoculate recipient mice, a modification of a technique described for intratracheal injection of organic antigen was used (24). Recipient mice were anesthetized with intraperitoneal pentobarbital $(80 \mathrm{mg} / \mathrm{kg})$ and placed supine with the head elevated 45 degrees. A midline incision in the neck was made to expose the trachea. An 18-gauge blunt needle was then passed through the mouth into the trachea, and its position was verified visually. A polyethylene catheter (PE 10; Clay Adams, Parsippany, NJ) was threaded through the needle so that the catheter tip extended just beyond the needle in the mid-trachea. The inoculum $(0.1 \mathrm{ml})$ was then injected through the catheter into the lungs of the recipient mice, immediately followed by $0.25 \mathrm{ml}$ of air. The needle and catheter were then removed together, and the incision was sutured. Injected mice were placed prone for recovery from anesthesia.

Experimental design. Mice scheduled for inoculation with $P$. carinii received at least two weekly injections of anti-CD4 antibody before the first intratracheal inoculation. A second intratracheal inoculation of $P$. carinii organisms obtained from a separate group of infected athymic mice was given one week later to insure adequate deposition of organisms into the lower respiratory tract. Weekly injections of anti-CD4 antibody continued for $1-12 \mathrm{wk}$, when the mice were killed and examined for the presence of $P$. carinii infection. To study resolution of infection, a group of mice were treated with anti-CD4 antibody and two intratracheal inoculations of $P$. carinii, but the anti-CD4 injections were stopped $2 \mathrm{wk}$ after the second intratracheal inoculation.

Control experiments included the following protocols:

(a) weekly injections of anti-CD4 antibody without intratracheal injections of $P$. carinii (five mice);

(b) weekly injections of $0.2 \mathrm{ml}$ PBS with two intratracheal injections of $P$. carinii (six mice);

(c) weekly injections of $0.1 \mathrm{mg}$ rat IgG (Calbiochem-Behring Corp., San Diego, CA) in $0.2 \mathrm{ml}$ PBS with two intratracheal injections of $P$. carinii (six mice); and

(d) weekly injections of anti-CD4 antibody with two intratracheal injections of lung tissue homogenate prepared from $P$. carinii-free BALB/c mice (three mice).

Flow cytometry. Thymuses and spleens from selected control and anti-CD4-treated mice were removed and dissociated mechanically into RPMI 1640 medium containing $100 \mathrm{U} / \mathrm{ml}$ penicillin, $100 \mu \mathrm{g} / \mathrm{ml}$ streptomycin, $10 \mathrm{mM}$ Hepes, and $2 \mathrm{mM}$ glutamine (all from Gibco Laboratories, Grand Island, NY). The medium was also supplemented with $5 \%$ fetal bovine serum (J. R. Scientific, Woodland, CA). Whole blood was removed by cardiac puncture and purified by Ficoll-Hypaque centrifugation (25). Red blood cells were lysed with $0.08 \mathrm{M}$ ammonium chloride. Cells were subsequently washed with PBS containing $0.1 \%$ BSA and $0.01 \%$ sodium azide. Cells were placed into 96 well V-bottom microtiter plates $\left(10^{6}\right.$ cells/well $)$ and incubated $20 \mathrm{~min}$ at $4^{\circ} \mathrm{C}$ with appropriate dilutions of monoclonal antibodies or lectins.

The following reagents were obtained from Becton Dickinson Monoclonal Center (Mountain View, CA): biotin-and FITC-conjugated anti-CD8 (anti-Ly-2, hybridoma 53-6.7) (26); phycoerythrinconjugated anti-CD4 (anti-L3T4, hybridoma GK1.5) (12); biotin-and FITC-conjugated anti-Thy-1.2 (hybridoma 30-H12) (26); and FITCconjugated mouse anti-rat kappa chain (hybridoma MAR 18.5) (27). Biotin-conjugated anti-CD4 was produced in our laboratories. Biotinconjugated peanut agglutinin (PNA) ${ }^{1}$ was obtained from E. Y. Laboratories, Inc. (San Mateo, CA). Phycoerythrin-conjugated PNA was obtained from Biomeda Corporation (Foster City, CA).

Spleen and blood cells were labeled with anti-Thy-1.2, anti-CD4, and anti-CD8 in combinations of two or three monoclonal antibodies. Thymocytes were labeled with anti-CD4, anti-CD8, and PNA to distinguish cortical and medullary thymocytes. Immature cortical thymocytes bind high levels of PNA and bear both CD4 and CD8, whereas mature medullary thymocytes bind low levels of PNA and bear either CD4 or CD8 (28). After the first incubation, cells were washed with PBS and then incubated with streptavidin-phycoerythrin or streptavidin-allophycocyanin (Becton Dickinson Monoclonal Center) (29). To examine binding of administered anti-CD4 and expression of CD4 on cortical and medullary thymocytes, cells incubated with PNA-phycoerythrin were co-incubated with FITC-conjugated MAR 18.5 alone. To examine expression of CD4 on thymocytes, cells incubated with PNA-phycoerythrin were co-incubated with unconjugated anti-CD4 followed by FITC-conjugated MAR 18.5. After washing, the cells were fixed with $1 \%$ paraformaldehyde in PBS.

Stained cells $\left(2 \times 10^{4}\right)$ were analyzed on a FACS 440 flow cytometer (Becton Dickinson Immunocytometry Systems, Mountain View, (A), using a helium neon laser set to excite FITC and phycoerythrin and an argon ion laser for allophycocyanin (29). Cells were also analyzed for forward and orthogonal scatter. Computer analysis was performed on a VAX 11/750 computer (Digital Equipment Corp., Marlboro, MA), and the data were analyzed using Electric Desk software.

Histologic examination of lung tissue. To examine lung tissue for the presence of $P$. carinii infection, mice were killed by a lethal intraperitoneal dose of pentobarbital and exsanguination. After cannulation of the trachea, the lungs were inflated with $10 \%$ formalin solution in PBS (Mallinckrodt Chemical Co., St. Louis, MO). Fixed lungs were removed en bloc, embedded in paraffin, and stained with methenamine-silver and hematoxylin-eosin stains. Slides of lung sections were examined for histologic abnormality and graded blindly for intensity of $P$. carinii infection.

The intensity or extent of pulmonary infection was scored with a semiquantitative grading technique modified from previously described methods (30-32). Previous methods to grade intensity of infection have been based on the percentage of alveoli containing $P$. carinii. During our blinded slide review it became apparent that lungs with focal alveolitis consistently had foci of infection immediately adjacent to terminal bronchiolar units. Alveoli midway between adjacent terminal bronchiolar units were free of signs of infection. As $P$. carinii infection increased in intensity, alveoli more distal to the terminal bronchiolar units became involved. With moderate infection, alveoli extending between adjacent terminal bronchioles were involved. In heavily infected lungs, the relationship to the bronchioles was lost. Therefore, we modified our semiquantitative scale to correspond to the

1. Abbreviations used in this paper: PNA, peanut agglutinin. 
spread of $P$. carinii first into alveoli adjacent to terminal bronchioles and subsequently into more distal airspaces. This scale was as follows: $0=$ no $P$. carinii present; $1=$ trace infection, random cyst(s) in scattered alveoli; 2 = focal alveolitis, alveoli immediately adjacent to terminal bronchioles contain cysts and alveoli midway between bronchioles are clear; 3 = moderate alveolitis, bridging between adjacent bronchiolar units by alveoli containing $P$. carinii; and $4=$ extensive alveolitis, massive involvement of alveolar spaces with $P$. carinii, and loss of relationship to terminal bronchiole.

Statistics. Data were expressed as mean $\pm \mathrm{SE}$ and analyzed by analysis of variance (33). Significant differences were accepted at $P \leq 0.05$.

\section{Results}

Depletion of $\mathrm{CD}^{+}$cells with anti-CD4 antibody. Flow cytometric analysis of spleen and blood cells from $P$. carinii-infected mice administered 2, 6, or 10 weekly injections of antiCD4 antibody showed depletion of CD4-positive T lymphocytes in comparison to uninfected control mice injected with PBS or rat IgG (Fig. 1). When calculated as a percentage of total lymphocytes, spleen cells from mice given 10 weekly injections of anti-CD4 antibody contained $0 \%$ CD4 ${ }^{+}$cells (Table I). The percentages of lymphocytes that expressed the CD8 marker or neither CD4 or CD8 were also not altered by antiCD4 treatment (Table 1). Treatment with anti-CD4 antibody alone did not result in signs of clinical illness or weight loss in comparison to normal mice.

Although the anti-CD4 antibody targeted and depleted CD4-positive cells in the spleen and peripheral blood, little antibody was found on the surface of cells in the thymus using an antibody to rat kappa chain (data not shown). Furthermore, there was virtually no change in the proportion of thymocyte subsets detected by staining with anti-CD4 and anti-CD8 $\left(\mathrm{CD}^{+} / \mathrm{CD}^{+}\right.$thymocytes: $67 \pm 3 \%$ treated vs. $64 \pm 2 \%$ control; $\mathrm{CD}^{+} / \mathrm{CD}^{-}$thymocytes: $18 \pm 1$ vs. $16 \pm 1 \%$ ). An analysis of the levels of CD4 on thymocyte subpopulations indicated that most CD4 sites on $\mathrm{CD}^{+}{ }^{+}$thymocytes had not been targeted or modulated in their expression (data not shown).

Frequency of infection in treated and control mice. In mice treated with anti-CD4 antibody and then given two intratracheal inoculations of $P$. carinii, infection with $P$. carinii was visible on methenamine-silver-stained sections of lung tissue from 1 to $12 \mathrm{wk}$ after the second intratracheal inoculation. The results of an experimental protocol analyzing mice 8-12 wk after intratracheal inoculation with $P$. carinii organisms are

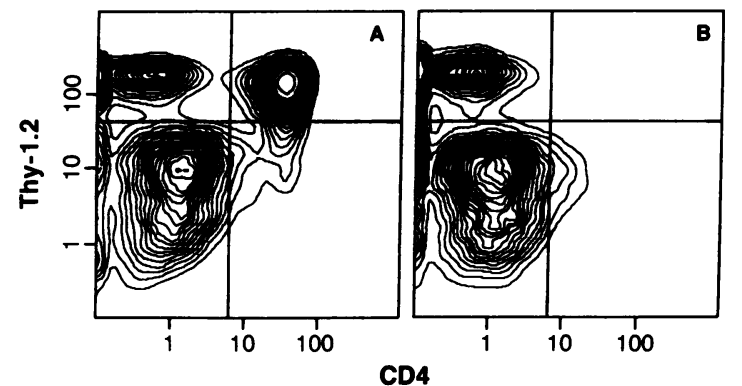

Figure 1. Depletion of $\mathrm{CD}^{+} \mathrm{T}$ cells in spleens of anti-CD4 treated mice: two-color plots of dispersed cells from mice given 10 weekly injections of either rat $\operatorname{lgG}(A)$ or anti-CD4 antibody $(B)$. Cells that are both Thy-1.2 $2^{+}$and $C D 4^{+}$are present in the upper right quadrant of $A$ and absent in $B$.
Table I. Percentages of Spleen Cells Bearing T Lymphocyte Markers in Mice Given 10 Weekly Injections of Anti-CD4 Antibody

\begin{tabular}{cccc}
\hline Mice & $\mathrm{CD}^{+} /$Thy-1.2 & $\mathrm{CD}^{+} /$Thy $-1.2^{+}$ & $\mathrm{CD}^{-} / \mathrm{CD}^{-} /$Thy-1.2 \\
& \multicolumn{4}{c}{} \\
Control (rat IgG) & $13 \pm 3$ & $13 \pm 1$ & $2 \pm 0$ \\
Anti-CD4 treated & 0 & $16 \pm 1$ & $3 \pm 0$ \\
\hline
\end{tabular}

Data represent the mean \pm SEM percentage of total lymphocytes for four mice from each group.

shown in Fig. 2. The percentage of mice with infection ranged from 50 to $100 \%$ in groups of animals studied at earlier times after inoculation with $P$. carinii. More recent protocols have resulted in higher percentages of infected mice than earlier protocols, perhaps reflecting experience with intratracheal inoculation of $P$. carinii organisms or better standardization of the inoculum. Mice with $P$. carinii infection did not appear clinically ill, and weight gain was comparable to control mice (data not shown). None of the control mice housed in filtered cages developed infection with $P$. carinii or any histologic abnormality in the pulmonary parenchyma when studied at 4 and $8 \mathrm{wk}$. When mice were treated with anti-CD4 antibody and housed in unfiltered cages adjacent to mice with $P$. carinii infection, a small percentage of the animals became lightly infected, presumably by airborne transfer of organisms from the infected animals. Similar observations have been reported by Walzer and colleagues in nude mice (8).

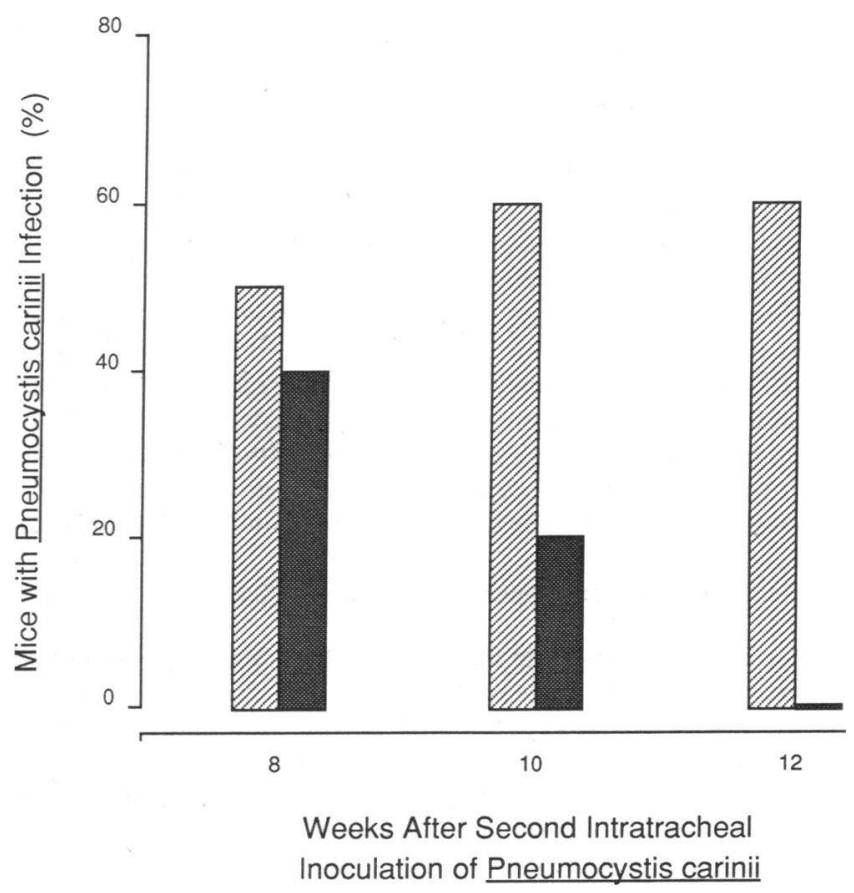

Figure 2. Percentage of mice with $P$. carinii infection. Data at each time point represent the results for at least five mice. Hatched bars, Mice given two intratracheal inoculations of $P$. carinii organisms and weekly anti-CD4 antibody; shaded bars, mice given two intratracheal inoculations of $P$. carinii and anti-CD4 treatment stopped 2 wk after the second intratracheal inoculation. 
$P$. carinii-infected mice were able to clear pulmonary infection when treatment with anti-CD4 antibody was stopped. This was demonstrated in a group of mice inoculated with $P$. carinii organisms, in which the anti-CD4 antibody treatments were discontinued $2 \mathrm{wk}$ after the second inoculation. When these mice were killed at 8,10 , and $12 \mathrm{wk}$, the percentage of mice infected was lower than in a concurrent group of mice with continued anti-CD4 treatment (Fig. 2). The percentage of mice with demonstrable infection showed a steady decline in the group without anti-CD4 treatment, such that no infection was present in these mice $12 \mathrm{wk}$ after the second intratracheal inoculation. In comparison, $60 \%$ of animals with continued anti-CD4 antibody treatments were infected at $12 \mathrm{wk}$.

Histopathology of $P$. carinii infection. Lung tissue from mice killed $3 \mathrm{~d}$ after the second intratracheal injection of $P$. carinii showed essentially normal histology by hematoxylineosin stain (Fig. $3 \mathrm{~A}$ ) and only rare intra-alveolar cysts by methenamine-silver stain (not shown). By $7 \mathrm{~d}$ after the second intratracheal injection, lung tissue clearly showed increased numbers of $P$. carinii organisms. In animals with focal infection, involved alveoli were present adjacent to the conducting airways, while moderate and extensive infection included progressively more alveoli (Fig. $3 \mathrm{~B}$ ). Involved alveoli contained abundant alveolar macrophages, often with vacuolated cytoplasm, as well as the characteristic eosinophilic exudate (Fig. 3 $B)$. In addition, a periarteriolar lymphocytic infiltrate was consistently present, usually in close proximity to alveoli containing $P$. carinii. Methenamine-silver-stained sections showed clusters of $P$. carinii cysts easily visible within the alveolar spaces of infected mice (Fig. $3 C$ ). Trophozoite forms of $P$. carinii were also visible in touch preparations of lung tissue stained with Diff-Quik (not shown).

When methenamine-silver-stained slides of lung tissue from the $P$. carinii-infected mice were graded for intensity of infection, a stable and persistent infection was evident up to 12 wk after the second intratracheal inoculation of $P$. carinii organisms (Fig. 4). Lymphocyte-depleted mice killed $3 \mathrm{~d}$ after intratracheal inoculation showed only rare intra-alveolar cysts. Control mice given intratracheal inoculations but no anti-CD4 antibody also showed no residual $P$. carinii organisms by 2 wk after the second inoculation. Therefore, $P$. carinii present in mice depleted of CD4-positive lymphocytes did not represent residual organisms from the inoculum, but probably represented organisms proliferating in situ.

\section{Discussion}

The results of these experiments demonstrate that pulmonary infection with $P$. carinii can be reproducibly established in the lungs of mice depleted of helper $\mathrm{T}$ lymphocytes by treatment with anti-CD4 antibody. In comparison to other animal models of $P$. carinii infection, this model may provide new information about the pathogenesis of $P$. carinii infection.

Because this new model of $P$. carinii infection allows precise control over the time course of experimental infection, involves a well-characterized immune defect, and permits the study of clearance of infection, it has advantages in comparison to existing experimental models. $P$. carinii infection does not occur in immunocompetent animals, and all experimental models of infection require some form of immunosuppres- sion. Corticosteroid-treated rats have been used extensively as an experimental model of $P$. carinii infection (34) after both reactivation of latent infection and intratracheal inoculation of $P$. carinii organisms (35). Unfortunately, recent changes in commercial breeding techniques have made it difficult to establish infection in rats treated with corticosteroids $(36,37)$, and the multiple biologic effects of corticosteroids (38) confound the study of specific host responses or treatment of $P$. carinii infection. Congenitally athymic mice also develop lowintensity $P$. carinii infection with advanced age (8) and have been used as a model of $P$. carinii pneumonia, but this form of immunodeficiency cannot be reversed to study clearance of infection. In addition, alterations in the host defense mechanisms of athymic mice extend beyond the recognized deficit in circulating $\mathrm{T}$ lymphocytes to include exaggerated macrophage and natural killer cell function as well (39).

Normal host defenses against $P$. carinii infection have not been clarified, but it is likely that a defect in cell-mediated immunity is necessary for infection to occur (40). Cell-mediated immunity is critically dependent on lymphocytes bearing the glycoprotein CD4 (12). In mice, CD4 is present on the surface of helper/inducer $T$ lymphocytes but not macrophages (41). Treatment of mice with anti-CD4 antibody has been shown previously to produce profound but selective depletion of helper T lymphocytes in blood, lymph node, and spleen (13, $14,19)$. The dose of anti-CD4 antibody used in this study depleted CD4-positive $\mathrm{T}$ cells in spleen and peripheral blood but did not significantly affect the $T$ cell precursor population in the thymus. Our ability to induce $P$. carinii infection in such mice depleted of CD4-bearing cells suggests that helper T lymphocytes are important in host defense against this pathogen. The reported induction of $P$. carinii infection in rats treated with cyclosporine also supports this idea (42).

Although our experiments implicate helper T lymphocytes in host defense against $P$. carinii infection, helper T lymphocytes may not be the only form of host defense against $P$. carinii. It is possible that the perivascular infiltrates observed in our $P$. carinii-infected mice reflect recruitment into the lungs of effector lymphocytes other than CD4-bearing cells. Alveolar macrophages (43), polymorphonuclear leukocytes (44), and alveolar epithelial cells (45-47) may also be involved in the pathogenesis of infection. The selective immunosuppression used in the model described here will allow investigators for the first time to study the role of these cells as well as helper $\mathrm{T}$ lymphocytes in host defense against $P$. carinii infection.

These experiments also delineate possible modes of spread of $P$. carinii within the lung. In mice with focal alveolitis, in which small numbers of alveoli were involved with infection, the involved alveoli were consistently adjacent to terminal bronchioles. As the extent of infection increased, interalveolar spread occurred, and alveoli more distal to bronchioles became involved. We cannot be absolutely sure that increasing extent of infection corresponds to progression of infection, as would occur in a single subject over time. However, the patterns we observed in this model suggest that after direct instillation of $P$. carinii into the airways, the earliest infection involves peribronchiolar alveoli, with subsequent spread to adjacent alveoli, and ultimately throughout the lung. It is not known whether a similar mode of intrapulmonary spread of $P$. carinii occurs in patients with AIDS. The source of $P$. carinii 

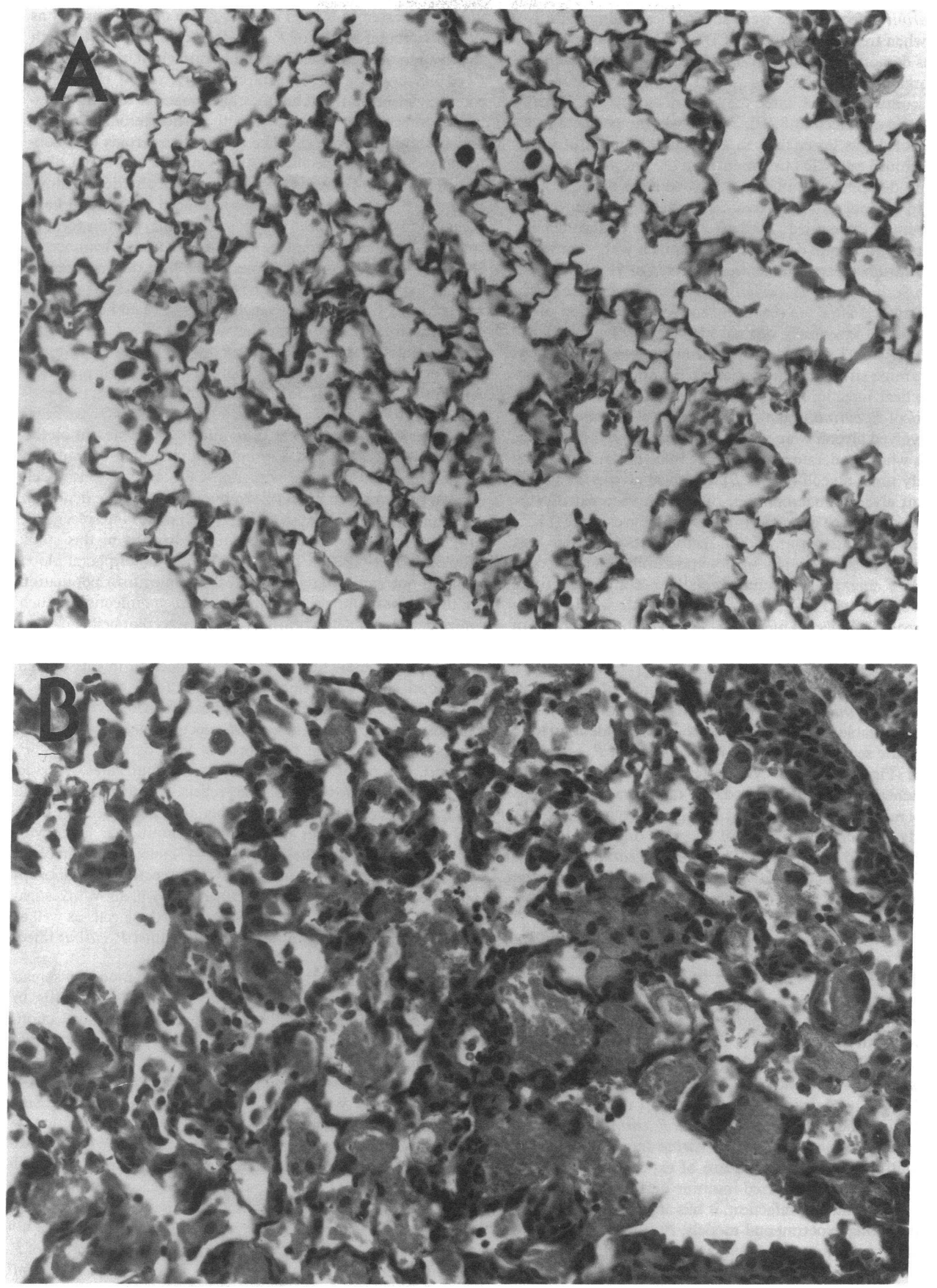


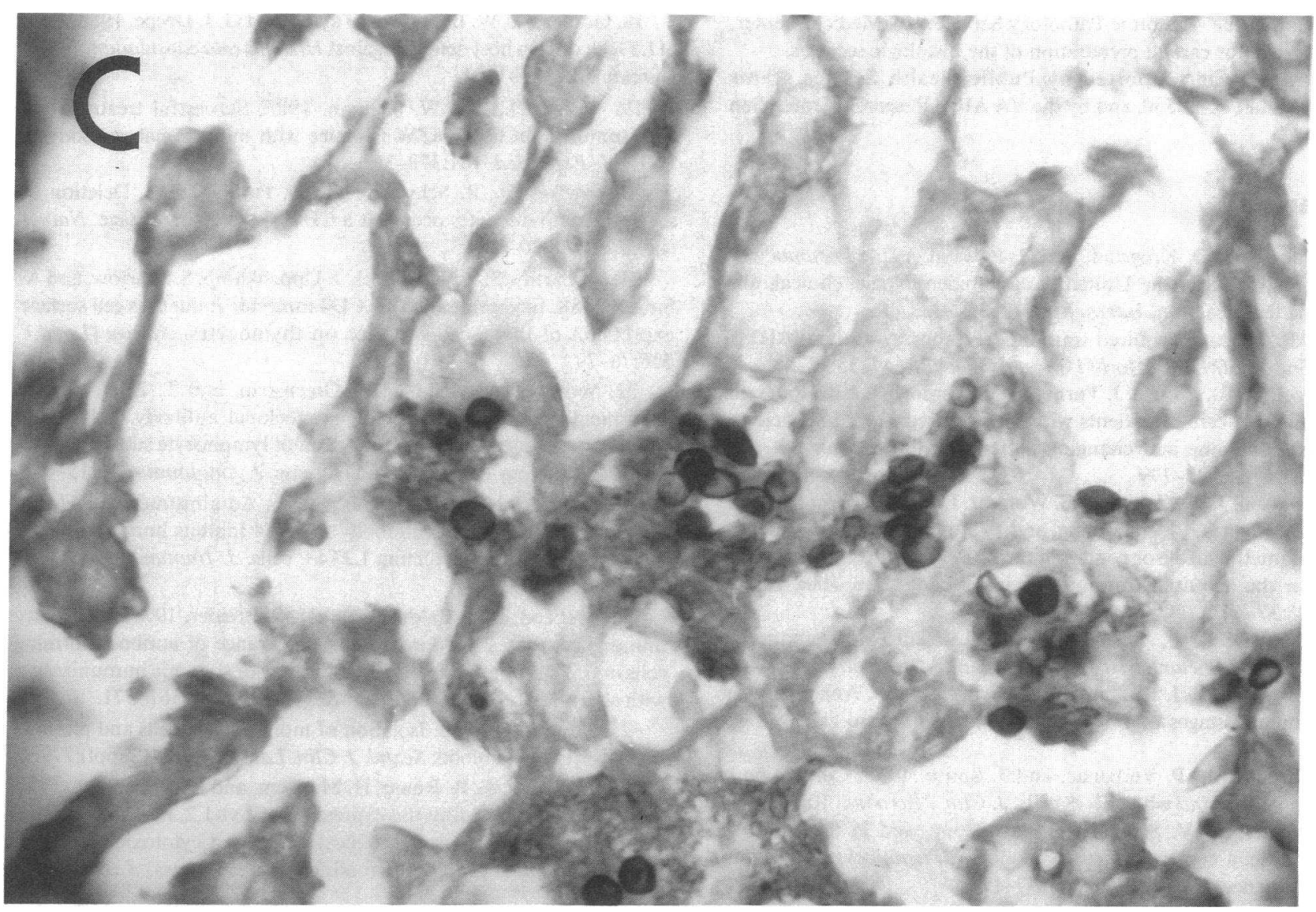

Figure 3. Histopathology of $P$. carinii infection. (Opposite) $A$, Antibody-treated mouse $3 \mathrm{~d}$ after second inoculation with $P$. carinii. Histology is normal; hematoxylin-eosin stain, $\times 100$. B. Heavy infection with $P$. carinii. Antibody-treated mouse $10 \mathrm{wk}$ after second inoculation with $P$. carinii. Alveolar spaces contain macrophages and eosinophilic exudate. Hematoxylin-eosin stain, $\times 100$. (Above) $C$, Same animal as in $B$. Characteristic oval and crescentic cyst forms of $P$. carinii. Silver methenamine stain, $\times 200$.

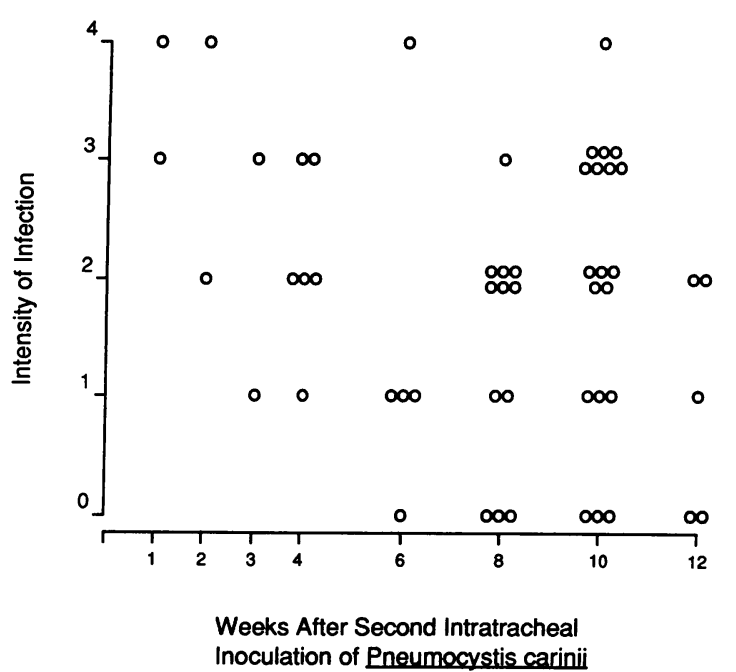

Figure 4. Intensity of $P$. carinii infection in anti-CD4-treated mice given two intratracheal inoculations of $P$. carinii organisms. The intensity of infection visible on methenamine-silver-stained slides was graded from 1 to 4 (see text). A grade of 0 means that no organisms were visible in the lung parenchyma. Analysis of variance indicated no significant differences in intensity of infection at the different times studied. infection in humans has not been identified. However, patients who are seropositive for the AIDS virus but without pulmonary symptoms do not have demonstrable $P$. carinii in lung samples $(48,49)$, suggesting that $P$. carinii pneumonia in AIDS may be an acquired airborne infection.

In summary, we report a new experimental model of pulmonary infection with $P$. carinii in mice depleted of helper $T$ lymphocytes. Infection with $P$. carinii can be reproducibly established in lymphocyte-depleted mice by intratracheal inoculation of $P$. carinii organisms derived from chronically infected athymic mice. The resultant infection is persistent and stable in intensity for up to 3 mo with continued antibody treatment, but is cleared spontaneously when antibody treatments are stopped. Whether $P$. carinii infection in mice persistently depleted of helper T lymphocytes with anti-CD4 antibody is ultimately fatal will require additional experiments over longer periods of time. This model of $P$. carinii infection provides new opportunities for research into the immunopathogenesis and treatment of $P$. carinii pneumonia, an important cause of mortality in patients with AIDS.

\section{Acknowledgments}

The authors express their appreciation to Drs. Martin F. Heyworth, Jeffrey L. Curtis, and H. Benfer Kaltreider for helpful advice, and to 
George Gan of the Anatomic Pathology Service, VA Medical Center, San Francisco, for careful preparation of the histologic sections.

This work was supported by Public Health Service grants HL-29246 and DK-38550, and by the VA AIDS Research Center, San Francisco.

\section{References}

1. Walzer, P., D. Krogstad, and P. Rawson. 1974. Pneumocystis carinii pneumonia in the United States: epidemiologic, clinical, and diagnostic features. Ann. Intern. Med. 80:83-93.

2. 1986. Update: acquired immunodeficiency syndrome (AIDS)United States. MMWR (Morbid. Mortal. Week. Rep.). 35:17-21.

3. Wachter, R., J. Luce, J. Turner, P. Volberding, and P. Hopewell. 1986. Intensive care of patients with the acquired immunodeficiency syndrome: outcome and changing patterns of utilization. Am. Rev. Respir. Dis. 134:796-799.

4. Wharton, J., D. Coleman, C. Wofsy, J. Luce, W. Blumenfeld, W. Hadley, L. Ingram, P. Volberding, and P. Hopewell. 1986. Trimethoprim-sulfamethoxazole or pentamidine for Pneumocystis carinii pneumonia in the acquired immunodeficiency syndrome. Ann. Intern. Med. 105:37-44.

5. Blumenfeld, W., and J. Griffiss. 1989. In vitro differentiation of human-derived Pneumocystis carinii. J. Clin. Microbiol. 27:480-485.

6. Cushion, M., J. Ruffolo, and P. Walzer. 1988. Analysis of the developmental stages of Pneumocystis carinii in vitro. Lab. Invest. 58:324-331.

7. Bartlett, M., P. Verbanac, and J. Smith. 1979. Cultivation of Pneumocystis carinii with WI-38 cells. J. Clin. Microbiol. 10:796-799.

8. Walzer, P., V. Schnelle, D. Armstrong, and P. Rosen. 1977. Nude mouse: a new experimental model for Pneumocystis carinii infection. Science (Wash. DC). 197:177-179.

9. Walzer, P., C. Kim, M. Linke, C. Pogue, M. Huerkamp, C. Chrisp, A. Lerro, S. Wixson, E. Hall, and L. Shultz. 1989. Outbreaks of Pneumocystis carinii pneumonia in colonies of immunodeficient mice. Infect. Immun. 57:62-70.

10. Frenkel, J., J. Good, and J. Schultz. 1966. Latent Pneumocystis infections of rats, relapse, and chemotherapy. Lab. Invest. 15:15591577.

11. Fauci, A., A. Macher, D. Longo, H. Lane, A. Rook, J. Masur, and E. Gelmann. 1984. NIH conference. Acquired immunodeficiency syndrome: epidemiologic, clinical, immunologic, and therapeutic considerations. Ann. Intern. Med. 100:92-106.

12. Dialynas, D., Z. Quan, K. Wall, A. Pierres, J. Quintans, M. Loken, M. Pierres, and F. Fitch. 1983. Characterization of the murine $\mathrm{T}$ cell surface molecule designated L3T4, identified by monoclonal antibody GK1.5: similarity of L3T4 to the human Leu-3/T4 molecule. J. Immunol. 131:2445-2449.

13. Ermak, T., and $\mathrm{H}$. Steger. 1988. $\mathrm{CD}^{-} / \mathrm{CD}^{-} \mathrm{T}$ cells: amplifcation in spleens of mice following in vivo treatment with monoclonal antibody anti-L3T4. Eur. J. Immunol. 18:231-235.

14. Wofsy, D., D. Mayes, J. Woodcock, and L. Seamna. 1985. Inhibition of humoral immunity in vivo by monoclonal antibody to L3T4: studies with soluble antigens in intact mice. J. Immunol. 135:1698-1701.

15. Titus, R., R. Ceredig, J. Cerottini, and J. Louis. 1985. Therapeutic effect of anti-L3T4 monoclonal antibody GK1.5 on cutaneous leishmaniasis in genetically-susceptible BALB/c mice. J. Immunol. 135:2108-2114.

16. Heyworth, M., J. Carlson, and T. Ermak. 1987. Clearance of Giardia muris infection requires helper/inducer $\mathrm{T}$ lymphocytes. $J$. Exp. Med. 165:1743-1748.

17. Minoprio, P., H. Eisen, M. Joskowicz, P. Pereira, and A. Coutinho. 1987. Suppression of polyclonal antibody production in Trypanosoma cruzi-infected mice by treatment with anti-L3T4 antibodies. J. Immunol. 139:545-550.
18. Gomez, A., W. Bullock, C. Taylor, and G. J. Deepe. 1988. Role of L3T4+ cells in host defense against Histoplasma capsulatum. Infect. Immun. 56:1685-1691.

19. Wofsy, D., and W. Seaman. 1985. Successful treatment of autoimmunity in NZB/NZW F1 mice with monoclonal antibody to L3T4. J. Exp. Med. 161:378-391.

20. Fowlkes, B., R. Schwartz, and D. Pardoll. 1988. Deletion of self-reactive thymocytes occurs at a $\mathrm{CD} 4+8+$ precursor stage. Nature (Lond.). 334:620-623.

21. McCarthy, S., A. Kruisbeek, I. Uppenkamp, S. Sharrow, and A. Singer. 1988. Engagement of the CD4 molecule influences cell surface expression of the T-cell receptor on thymocytes. Nature (Lond.). 336:76-79.

22. Wofsy, D., N. Chiang, J. Greenspan, and T. Ermak. 1988. Treatment of murine lupus with monoclonal antibody to L3T4. I. Effects on the distribution and function of lymphocyte subsets and on the histopathology of autoimmune disease. J. Autoimmun. 1:415-431.

23. Gutstein, N., and D. Wofsy. 1986. Administration of $F(a b) 2$ fragments of monoclonal antibody to L3T4 inhibits humoral immunity in mice without depleting L3T4+ cells. J. Immunol. 137:34143419.

24. McLeod, E., J. Caldwell, and H. Kaltreider. 1978. Pulmonary immune responses of inbred mice: appearance of antibody-forming cells in C57BL/6 mice after intrapulmonary or systemic immunization with sheep erythrocytes. Am. Rev. Respir. Dis. 118:561-571.

25 . Boyum, A. 1968. Isolation of mononuclear cells and granulocytes from human blood. Scand. J. Clin. Lab. Invest. 21(Suppl):77-89.

26. Ledbetter, J., R. Rouse, H. Micklem, and L. Herzenberg. 1980 $T$ cell subsets defined by the expression of Lyt-1,2,3 and Thy- 1 antigens. Two parameter immunofluorescence and cytotoxicity analysis with monoclonal antibodies modifies current views. J. Exp. Med. 152:280-291.

27. Lanier, L., G. Gutman, D. Lewis, S. Griswold, and N. Warner. 1982. Monoclonal antibodies against rat immunoglobulin kappa chains. Hybridoma. 1:125-132.

28. Scollay, R., P. Barlett, and K. Shortman. 1984. T cell development in the adult murine thymus: changes in the expression of the surface antigens Ly2, L3T4, and B2A2 during development from early precursor cells to emigrants. Immunol. Rev. 82:79-103.

29. Lanier, L., J. Allison, and J. Phillips. 1986. Correlation of cell surface antigen expression on human thymocytes by multi-color flow cytometric analysis: implications for differentiation. J. Immunol. 137:2051-2057.

30. Kim, C., J. Foy, M. Cushion, D. Stanforth, M. Linke, H. Hendrix, and P. Walzer. 1987. Comparison of histologic and quantitative techniques in evaluation of therapy for experimental Pneumocystis carinii pneumonia. Antimicrob. Agents Chemother. 31:197-201.

31. Hughes, W., and B. Smith. 1984. Efficacy of diamino-diphenylsulfone and other drugs in murine Pneumocystis carinii pneumonitis. Antimicrob. Agents Chemother. 26:436-440.

32. Debs, R., W. Blumenfeld, E. Brunette, R. Straubinger, A. Montgomery, E. Lin, N. Agabian, and D. Papahadjopoulos. 1987. Successful treatment with aerosolized pentamidine of Pneumocystis carinii pneumonia in rats. Antimicrob. Agents Chemother. 31:37-41.

33. Zar, J. 1974. Biostatistical Analysis. Prentice-Hall, Inc., Englewood Cliffs, NJ. 130-150

34. Walzer, P. 1984. Experimental models of Pneumocystis carinii infections. In Pneumocystis carinii Pneumonia: Pathogenesis, Diagnosis, and Treatment. L. Young, editor. Marcel Dekker, Inc., New York. 7-76.

35. Bartlett, M., J. Fishman, S. Queener, M. Durkin, M. Jay, and J. Smith. 1988. New rat model of Pneumocystis carinii infection. J. Clin. Microbiol. 26:1100-1102.

36. Eisen, S. 1989. Decreased yield of Pneumocystis carinii from cortisonized rats. J. Parasitol. 75:82-85. 
37. Bartlett, M., M. Durkin, M. Jay, S. Queener, and J. Smith. 1987. Sources of rats free of latent Pneumocystis carinii. J. Clin. Microbiol. 25:1794-1795.

38. Cupps, T., and A. Fauci. 1982. Corticosteroid-mediated immunoregulation in man. Immunol Rev. 65:133-155.

39. Shultz, L., and C. Sidman. 1987. Genetically determined murine models of immunodeficiency. Annu. Rev. Immunol. 5:367-403.

40. Graves, D. 1989. Immunological studies of Pneumocystis carinii. J. Protozool. 36:60-69.

41. Crocker, P., W. Jefferies, S. Clark, L. Chung, and S. Gordon. 1987. Species heterogeneity in macrophage expression of the CD4 antigen. J. Exp. Med. 166:613-618.

42. Hughes, W., and B. Smith. 1982. Provocation of infection due to Pneumocystis carinii by cyclosporin A. J. Infect. Dis. 145:767.

43. Von Behren, L., and E. Pesanti. 1978. Uptake and degradation of Pneumocystis carinii by macrophages in vitro. Am. Rev. Respir. Dis. 118:1051-1059.

44. Pesanti, E. 1982. Effects of bacterial pneumonitis on development of pneumocystosis in rats. Am. Rev. Respir. Dis. 125:723-728.
45. Pesanti, E. 1987. Phospholipid profile of Pneumocystis carinii and its interaction with alveolar type II epithelial cells. Infect. Immun. 55:736-741.

46. Long, E., J. Smith, and J. Meier. 1986. Attachment of Pneumocystis carinii to rat pneumocytes. Lab. Invest. 54:609-615.

47. Walzer, P. 1986. Attachment of microbes to host cells: relevance of Pneumocystis carinii. Lab. Invest. 54:589-592.

48. Ognibene, F., H. Masur, P. Rogers, W. Travis, A. Suffredini, I. Feuerstein, V. Gill, B. Baird, J. Carrasquillo, J. Parillo, H. Lane, and J. Shelhamer. 1988. Human immunodeficiency virus infected individuals with no pulmonary symptoms often have evidence of nonspecific interstitial pneumonitis but not Pneumocystis carinii at bronchoscopy. Ann. Intern. Med. 104:874-879.

49. Coleman, D., J. Luce, J. Wilbur, J. Ferrer, B. Stephens, W. Margaretten, E. Wagar, W. Hadley, L. Pifer, and A. Moss. 1986. Antibody to the retrovirus associated with the acquired immunodeficiency syndrome (AIDS): presence in presumably healthy San Franciscans who died unexpectedly. Arch. Intern. Med. 146:713-715. 